Tropical Journal of Pharmaceutical Research June 2016; 15 (6): 1205-1213

ISSN: $1596-5996$ (print); 1596-9827 (electronic)

(C) Pharmacotherapy Group, Faculty of Pharmacy, University of Benin, Benin City, 300001 Nigeria.

All rights reserved.

\title{
Anti-cancer and antioxidant properties of phenolics isolated from Toona sinensis A Juss acetone leaf extract
}

\author{
Sharui Shan, Xuming Huang*, Mingxing Zhang and Yihua Shi \\ Department of Rehabilitation, The First Affiliated Hospital/School of Clinical Medicine of Guangdong Pharmaceutical University, \\ Guangzhou, China
}

*For correspondence: Email: 781607917@qq.com, shansharui@126.com; Tel: (86) 20-61335054; Fax: (86) 20-61335054

Received: 10 January 2016

Revised accepted: 28 May 2016

\begin{abstract}
Purpose: To investigate the antioxidant and anticancer activities of phenolics from the leaf extract of Toona sinensis (TS).

Methods: Acetone leaf extract of TS was screened for total phenolic and flavanoid contents, and the flanonoids were subjected to high performance liquid chromatographic (HPLC) analysis. Antioxidant properties were assessed via oxygen radical absorbance capacity (ORAC), peroxyl radical scavenging capacity (PSC) and cellular antioxidant activity (CAA), while anti-proliferative activity ins HepG2 cell line was assessed using methylene blue assay.

Results: The extract contained $36.02 \pm 0.24 \mathrm{mg}$ of gallic acid equiv/g dry weight (DW) and $20.24 \pm 1.73$ $\mathrm{mg}$ of catechin equiv/g DW of total phenolic and total flavonoid, respectively. The levels of rutin and quercitrin were 0.51 and $19.55 \mathrm{mg} / \mathrm{g}$, respectively. Epicatechin, gallic acid, quercitin, isoquercetin were not detected. The extract showed significant antioxidant potential and high anti-proliferation capacity with low cytotoxicity against HepG2 cell in vitro. The underlying mechanism of anti-proliferative effect was induction of apoptosis.

Conclusion: TS leaf extract possesses significant in vitro antioxidant properties and anti-proliferative effect against HepG2 cells, which make it a potential anticancer drug source.
\end{abstract}

Keywords: Toona sinensis, Phenolics, Antioxidants, HepG2 cells, Anti-proliferation

Tropical Journal of Pharmaceutical Research is indexed by Science Citation Index (SciSearch), Scopus, International Pharmaceutical Abstract, Chemical Abstracts, Embase, Index Copernicus, EBSCO, African Index Medicus, JournalSeek, Journal Citation Reports/Science Edition, Directory of Open Access Journals (DOAJ), African Journal Online, Bioline International, Open-J-Gate and Pharmacy Abstracts

\section{INTRODUCTION}

Phytochemicals are plant-based non-nutrient secondary metabolites, which provide multiple positive health effect. These metabolites are increasingly recognized as efficacious components in the prevention and management of chronic disease, such as cancer, diabetes, and cardiovascular diseases [1].

Toona sinensis A. Juss is a deciduous tree which belongs to the family Meliaceae. All parts of TS are medicinally useful. Indeed the plant possesses many biological functions such as antitumor activity [2], antioxidant capacity [3], and anti-inflammatory properties [4]. It is also used for treating severe acute respiratory syndrome [5], and for improving hyperglycemia and dyslipidemia [6]. The young leaves of TS are popular in traditional Chinese medicines and have been used for long as a safe vegetable source [7]. Non-polar extracts of TS leaves contain constituents that can prevent type-2 diabetes and hepatosteatosis [8]. Previous studies showed that TS leaves possess antioxidative activity and anti-inflammatory activities [9]. TS is used for treatment of liver cancer in Gansu province of China [10]. Although the anti- 
diabetic, antioxidant and anti-inflammatory activities of TS leaves have been reported, there is lack of information on their phenolic profiles, cellular antioxidant activity and in vitro antiproliferative activity.

\section{EXPERIMENTAL}

\section{Chemicals and materials}

2,2'-Azobis-amidino-propane (ABAP), catechin hydrate, gallic acid, Folin-Ciocalteu reagent and dichlorofluorescin diacetate (DCFH-DA) were obtained from Sigma Chemical Co. (St. Louis, MO, US). All solvents used were of analytical grade. Williams medium E (WME), insulin, and other cell culture media were purchased from Gibco U.S. Biotechnology Co. Fetal bovine serum (FBS) was bought from Tianhang Biotech Co. Inc. (Zhejiang, China). HepG2 cell line was obtained from the Sun Yat-sen University Culture Collection.

\section{Samples treatment and preparation}

One kilogram of the leaves was collected from Anhui-China in spring 2014. The leaves were washed with distilled water to remove dirt, followed by freezing at $-80{ }^{\circ} \mathrm{C}$ for $24 \mathrm{~h}$ and vacuum freeze-drying. The dried leaves were ground into powders (60 mesh) and stored at -80 ${ }^{\circ} \mathrm{C}$ prior to analysis.

\section{Extraction procedures}

The powder extraction procedure was a modification of the classical method described by $\mathrm{Chu}$ et al [11]. The powder $(10 \mathrm{~g})$ was homogenized with chilled acetone $(80 \%)$ for 5 min. The homogenate was filtered under vacuum, and the residue was re-extracted and filtered three times. The extracts were pooled in flasks and evaporated at $45{ }^{\circ} \mathrm{C}$ until no acetone was left. The residue was dissolved in a little volume of distilled water and stored at $-40{ }^{\circ} \mathrm{C}$ until used.

\section{Estimation of total phenolic content}

Total phenolic content was determined as gallic acid equivalent using gallic acid standard curve [12], and the final value was expressed as milligram of gallic acid equivalent (GAE) per gram DW.

\section{Measurement of total flavonoid content}

The total flavonoid content was determined using the sodium borohydride/chloranil-based method as described earlier [13]. Values were calculated using catechin hydrate standard curve and expressed as milligram of catechin equivalent $(\mathrm{CE}) / \mathrm{g}$ DW. Data are showed as mean \pm SD.

\section{Analysis of flavonoids by HPLC}

Flavonoid compounds in the sample extract were quantified using HPLC. HPLC system was assembled with Waters Associates chromatography (Waters Corp, Milford, US), and spectrophotometer set at $360 \mathrm{~nm}$ was used. A Sun Fire C18 phase column ( $5 \mu \mathrm{m}$ particle size, $250 \mathrm{~mm} \times 4.6 \mathrm{~mm}$ ) was employed for chromatographic separation at $30{ }^{\circ} \mathrm{C}$. The binary mobile phase consisted of methanol $(A)$ and water (B). After injection of $10 \mu \mathrm{L}$ sample, the system was eluted with $5 \%$ A for 5 min; then increased to $10,15,20$ and $45 \%$ each at 5-min intervals. Then the gradient solvent $\mathrm{A}$ was increased to $100 \%$ in 5 min, kept at $100 \%$ for 10 $\mathrm{min}$, and recycled back to $5 \%$ after $5 \mathrm{~min}$, and kept for $5 \mathrm{~min}$ prior to running the next sample. All process flow rate was $1.0 \mathrm{~mL} / \mathrm{min}$. The peaks were identified through their retention times by comparing with UV-visible spectra of standards.

\section{Antioxidant assays}

Total antioxidant activities were determined by hydrophilic peroxyl radical scavenging capacity assay and oxygen radical scavenging capacity assay. Hydrophilic peroxyl radical scavenging capacity of the extract was evaluated using the method as outlined previously [14]. In a run, pure compounds or sample extract appropriately diluted in phosphate buffer were transferred into reaction cells on a 96-well plate followed by the addition of DCFH. The reaction was initiated by adding ABAP and read at once. Each set of dilutions and control was added in triplicate in 96well plate. Fluorescence was monitored at 485 $\mathrm{nm}$ excitation and $535 \mathrm{~nm}$ emission in a fluorescent spectrophotometer (SoftMax systems, Molecular Devices, US). Result was presented as micromoles of vitamin $\mathrm{C}$ equivalent (VCE) per gram of sample.

Oxygen radical scavenging capacity was measured as described by Prior et al $[15,16]$, using black, clear-bottom, 96-well microplates. Extract diluent and trolox standard were added to appropriate wells and incubated at $37^{\circ} \mathrm{C}$ for 10 min. Fluoroscein working solution was added to each well and incubated at $37{ }^{\circ} \mathrm{C}$ for $20 \mathrm{~min}$. After incubation, freshly prepared ABAP was added to each well (except the control well) and the wells were immediately read in Fluoroskan Ascent FL plate-reader at excitation of $485 \mathrm{~nm}$ and emission of $535 \mathrm{~nm}$ for 35 cycles every 4.5 
min. ORAC value was expressed as mean micromoles of trolox equivalent (TE) per g DW.

\section{Cell culture}

HepG2 cells were cultured in WME, containing 2 $\mathrm{mM}$ L-glutamine, $10 \mathrm{mM}$ Hepes, $5 \mu \mathrm{g} / \mathrm{mL}$ insulin, $0.05 \mu \mathrm{g} / \mathrm{mL}$ hydrocortisone, $50 \mu \mathrm{g} / \mathrm{mL}$ streptomycin, 50 units $/ \mathrm{mL}$ penicillin, $5 \%$ FBS and $100 \mu \mathrm{g} / \mathrm{mL}$ gentamicin. Cells were incubated at $37{ }^{\circ} \mathrm{C}$ with $5 \% \mathrm{CO}_{2}$, and seeded/sub-cultured when in exponential growth phase.

\section{Cytotoxicity of extract against HepG2}

Cytotoxicity was measured as described formerly [17]. The concentration of extract that decreased cell numbers by $10 \%$ when compared to the control was considered to be cytotoxic.

\section{Cellular antioxidant activity (CAA)}

The cellular antixoidant activity of the extract was determined following the method of Wolfe et al [18]. HepG2 cells were seeded into black, clearbottom, 96-well microplate. Cell medium was removed after $24 \mathrm{~h}$ of seeding, and the cells were washed with PBS, and treated in triplicate with solutions containing different concentrations of quercetin or extracts plus DCFH-DA dissolved in antioxidant treatment medium for $1 \mathrm{~h}$. If a PBS wash was to be utilized, wells were washed with PBS followed by addition of ABAP solution. The microplate was read in a Fluoroskan Ascent FL plate-reader at excitation of $485 \mathrm{~nm}$ and emission of $535 \mathrm{~nm}$ for 13 cycles every $5 \mathrm{~min}$. The area under the fluorescence-versus-time curve was calculated to determine CAA value. $E_{50}$ values were converted to CAA values, which were expressed as micromoles of quercetin equivalent (QE) per $100 \mathrm{~g}$ of sample, using the mean $\mathrm{EC}_{50}$ value for quercetin from three separate experiments.

\section{Inhibition of cell proliferation}

The anti-proliferation effects of the extract were determined using cell methylene blue colorimetric assay [17]. The anti-proliferative effects were assessed by the $\mathrm{EC}_{50}$ values, expressed as milligrams of sample extract per milliliter.

\section{Assessment of apoptosis by flow cytometry}

The apoptosis of HepG2 cell was analyzed by flow cytometer employing an annexin V-FITC and PI apoptosis detection kit. In brief, the cells were treated with $0,4,6$ and $8 \mathrm{mg} / \mathrm{mL}$ of extract for $24 \mathrm{~h}$ followed by harvesting, washing and incubation with annexin V-FITC and PI at room temperature for $20 \mathrm{~min}$. Aluminum foil was used during all staining processes to avoid light and; the cells were analyzed by flow cytometer.

\section{Statistical analysis}

Statistical analysis was performed using SPSS software 13.0 (SPSS Inc., Chicago, IL, USA), while dose-effect analysis was done using Calcusyn software version 2.0 (Biosoft, Cambridge, UK). All data are reported as mean \pm $\operatorname{SD}(n=3)$.

\section{RESULTS}

\section{Total phenolic and flavonoid contents}

Measured values of total phenolic and flavonoid contents are given in Table 1. The total phenolic content of the leaf extract of TS was $36.02 \mathrm{mg}$ of GCE/g DW, which was less than reported level of polyphenolic content (79.90 mg of GCE/g) in TS leaf [19]. However, this value was 45.28 times and 98.25 times higher compared to spinach and cabbage, respectively [11]. This indicated that TS leaf is a good source of phenolics.

Total flavonoid content of TS leaves extract was $20.24 \pm 1.73 \mathrm{mg}$ of CE/g DW. This amount was relatively higher than the value reported earlier $(12.92 \pm 0.95 \mathrm{mg}$ of $\mathrm{CE} / \mathrm{g}$ sample) in the aqueous extract of TS leaf [20]. In the studied sample, contribution of total flavonoids to total phenolics was $32.92 \pm 2.65 \%$.

Table 1: Phytochemical content of TS leaf extract

\begin{tabular}{lc}
\hline Parameter & Value \\
\hline Total phenolics (mg of gallic acid & $36.02 \pm 0.24$ \\
equiv./g DW) & $20.24 \pm 1.73$ \\
$\begin{array}{l}\text { Total flavonoids (mg of catechin } \\
\text { equiv./g DW) }\end{array}$ & $32.92 \pm 2.65$ \\
$\begin{array}{l}\text { Percent contribution of total } \\
\text { flavonoids to total phenolics }(\%)\end{array}$ & $243.26 \pm 26.59$ \\
$\begin{array}{l}\text { PSC values }(\mu \mathrm{mol} \text { of vitamin C } \\
\text { equiv./g DW) }\end{array}$ & $328.84 \pm 32.75$ \\
$\begin{array}{l}\text { ORAC values ( } \mu \mathrm{mol} \text { of trolox } \\
\text { equiv./g DW) }\end{array}$ & \\
\hline Values are mean $\pm \mathrm{SD}(\mathrm{n}=3)$ & \\
& \\
Flavonoid compounds
\end{tabular}

Flavonoids such as quercitrin, rutin, epicatechin, gallic acid, quercitin and isoquercetin were identified and quantified by comparing retention times with those of authentic standards using HPLC method. Only two compounds quercitrin and rutin were detected and quantified at concentrations of $19.55 \mathrm{mg} / \mathrm{g} \mathrm{DW}(1.95 \%)$ and 
$0.51 \mathrm{mg} / \mathrm{g}$ DW (0.51\%), respectively (Table 2, Figure 1). Epicatechin, gallic acid, quercitin, and isoquercetin were below the detection limit.

Table 2: Content of antioxidant compounds of TS leaf extract (mg/g DW)

\begin{tabular}{lc}
\hline Compound & $\begin{array}{c}\text { Content (mg/g } \\
\text { of DW) }\end{array}$ \\
\hline Quercitrin & $19.55 \pm 0.55$ \\
Rutin & $0.51 \pm 0.02$ \\
Epicatechin & ND \\
Gallic acid & ND \\
Quercitin & ND \\
Isoquercetin & ND \\
\hline
\end{tabular}

\section{Total in vitro antioxidant activity}

Reactive oxygen species (ROS) have been reported as the causative factor in many chronic diseases. Oxidative stress caused by ROS can be prevented by natural antioxidant compounds [21]. The results of in vitro antioxidant activities of the extract are displayed in Table 1 and Figure 2. Although antioxidant activities of plant extracts can be determined by various methods, PSC and ORAC methods are the latest and more authentic techniques. PSC assay incorporates DCFH-DA as a fluorescent probe, and is suitable for analyzing both hydrophilic and lipophilic antioxidants. This method is reliable, sensitive, rapid, precise, and reproducible [22]. The PSC value was $243.26 \pm 26.59 \mu \mathrm{mol} \mathrm{VCE} / \mathrm{g} \mathrm{DW}$
(Table 1 and Figure 2). Food and pharmaceutical industries usually use oxygen radical absorbance capacity (ORAC) assay to test total antioxidant activity. In a typical ORAC assay, the loss of fluorescence of B-phycoerythrin is an indication of the degree of damage from its reaction with the peroxyl radical [16]. The antioxidant activity is valued by assessing the area under the fluorescence decay curve of the extract relative to that of the blank containing PBS [14]. The TS leaf extract had an ORAC value $328.84 \pm 32.75$ $\mu \mathrm{mol}$ TE/g DW (Table 1).

\section{Cellular antioxidant activity}

The kinetic of DCFH oxidation by peroxyl radicals generated from ABAP is exhibited in Figure 3. Increases in fluorescence due to formation of DCF were inhibited by quercetin or TS leaf extract in a dose-dependent manner. DCFH oxidation was suppressed whether the cells had been washed with PBS or not between the antioxidant and the ABAP treatments. The EC50 values of TS leaf extract by CAA were $1518.6 \pm$ $170.74 \mathrm{mg} / \mathrm{mL}$ in wash protocol, and $567.48 \pm$ $1845 \mathrm{mg} / \mathrm{mL}$ in no-wash protocol. The $\mathrm{EC}_{50}$ values were converted to CAA values, which gave $762.55 \pm 85.97 \mu \mathrm{mol} \mathrm{QE} / 100 \mathrm{~g}$ sample in wash protocol, and $1719.8 \pm 56.04 \mu \mathrm{mol} Q E / 100$ $\mathrm{g}$ sample in no-wash protocol. In other words, $44.34 \%$ of the constituents can enter the cells.

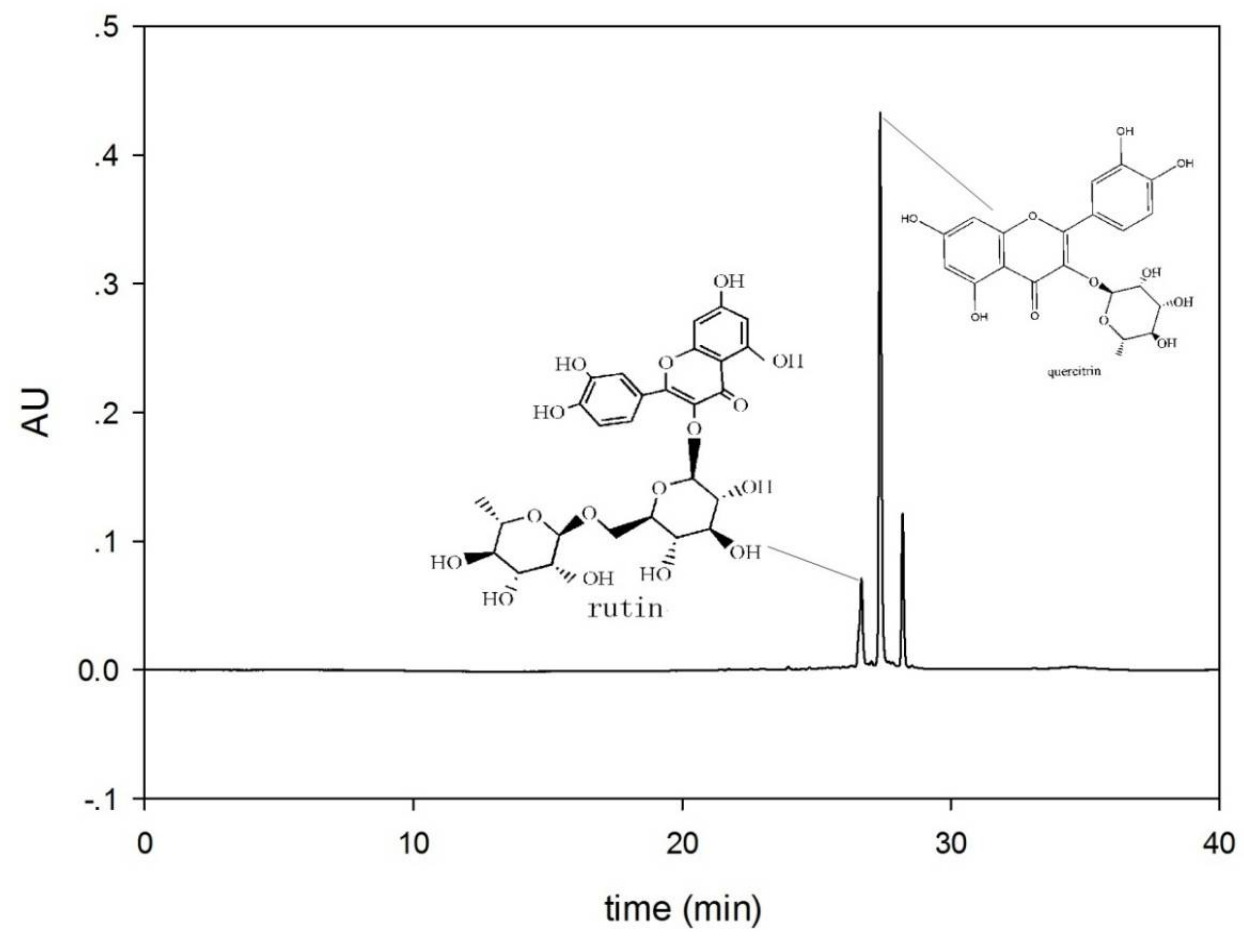

Figure 1: HPLC analysis of flavonoids from TS leaf extract 

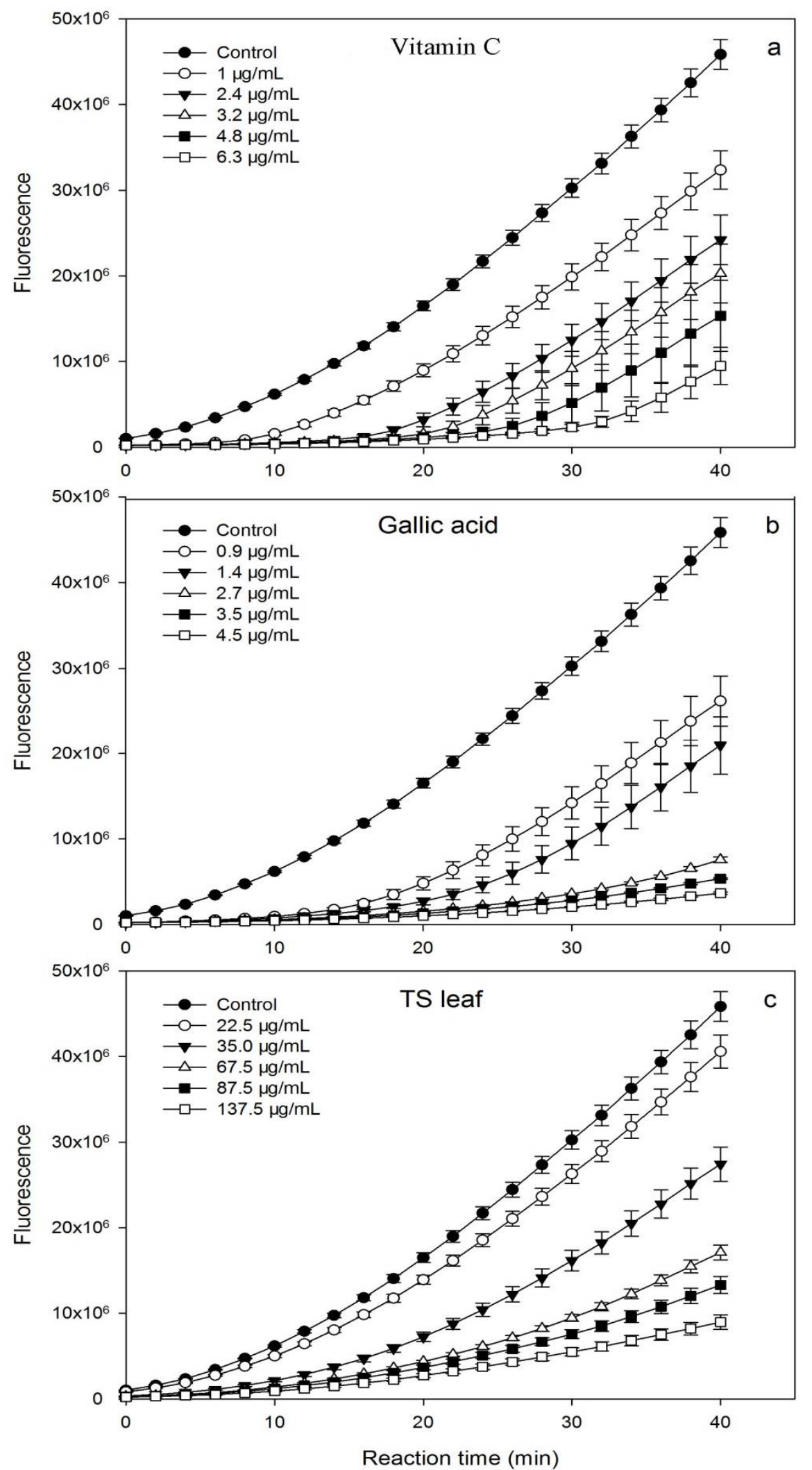

Figure 2: Time kinetics and dose-response of hydrophilic antioxidant activities of Vitamin $\mathrm{C}$ (a), gallic acid (b) and TS leaf extract $(c)($ mean $\pm S D, n=3)$ 

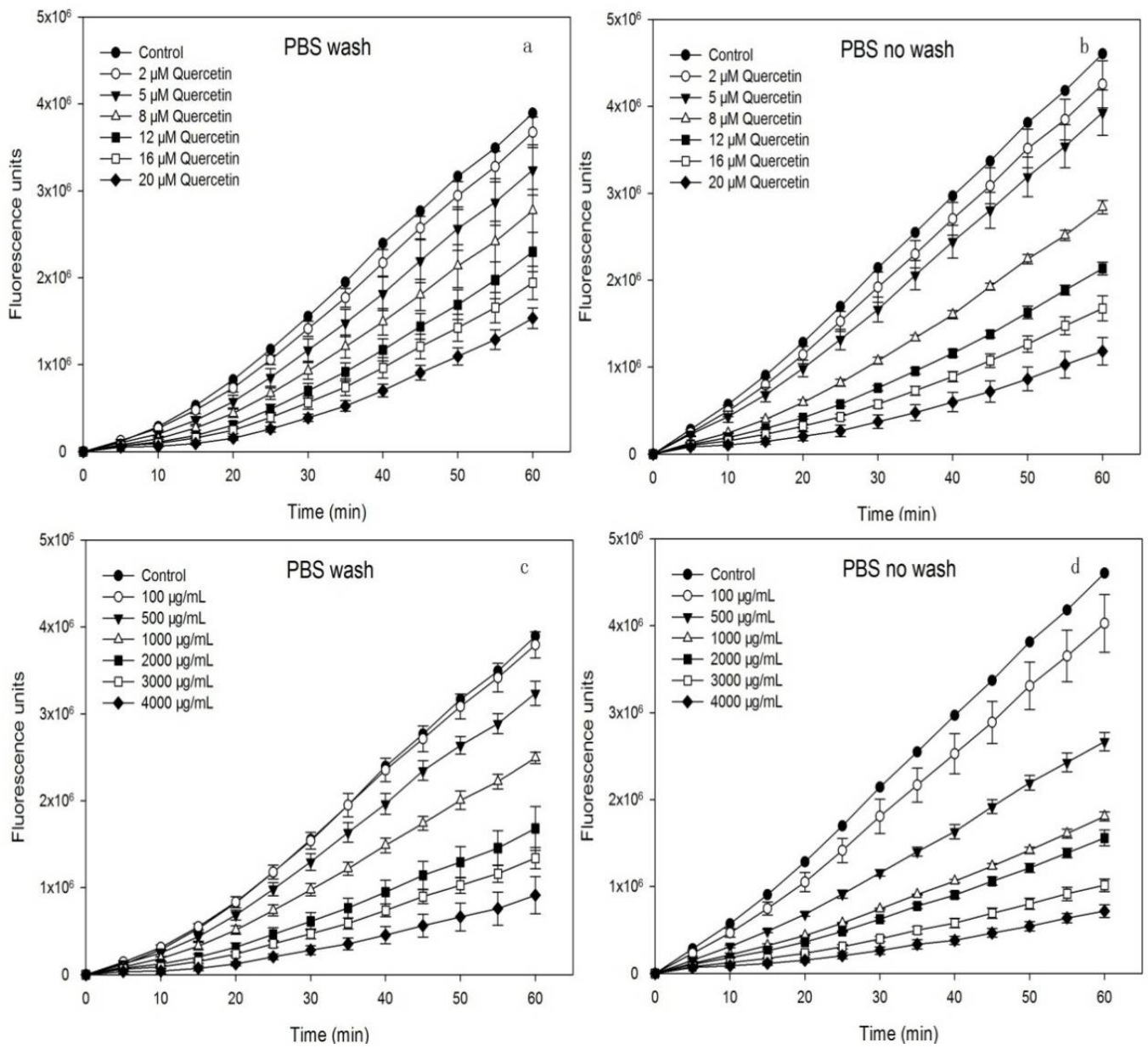

Figure 3: Peroxyl radical-induced oxidation of DCFH to DCF in hepG2 cells and the antioxidant activity by quercetin $(a, b)$ and TS leaf extract $(c, d)$ over time (Mean $\pm S D, n=3$ )

\section{Cellular antioxidant quality}

The cellular antioxidant qualities of the extract were evaluated from their CAA values, phenolic content and flavonoid content, and expressed as micromole of QE/100 $\mu \mathrm{mol}$ of phenolics or flavonoids. In the PBS wash protocol, CAA value of TS leaf extract relative to total phenolics was $3.60 \pm 0.43 \mu \mathrm{mol} Q E / 100 \mu \mathrm{mol}$; while CAA value relative to total flavonoids was $11.00 \pm 1.71 \mu \mathrm{mol}$ $\mathrm{QE} / 100 \mu \mathrm{mol}$. In the no-wash protocol, CAA value of the extract relative to total phenolics was $8.12 \pm 0.26 \mu \mathrm{mol} Q \mathrm{QE} / 100 \mu \mathrm{mol}$; while CAA value relative to total flavonoids was $24.75 \pm 1.48 \mu \mathrm{mol}$ $\mathrm{QE} / 100 \mu \mathrm{mol}$.

\section{Anti-proliferative and cytotoxic effect on HepG2 cancer cells}

Figure 4 shows anti-proliferative activity and cytotoxic effects of the extract. The median effective dose $\left(\mathrm{EC}_{50}\right)$ for inhibition of HepG2 cell proliferation was $7.45 \pm 0.37 \mathrm{mg} / \mathrm{mL}$.

\section{Induction of apoptosis by TS leaf extract}

Pro-apoptotic effect is regarded as the most important route for anti-proliferative action of phytochemicals toward cancer cells [23]. The apoptosis effect of TS leaf extract was assayed by flow cytometric analysis and the results of annexin V-FITC/PI staining assay are displayed in Figure 5. It was observed that the extract exhibited apparent effect on the percentage of early apoptotic cells. HepG2 cells treated with the leaf extract had an increase in the ratio of early stage apoptosis cells compared to the blank group. Remarkable enhancement was observed in cells treated with $6 \mathrm{mg} / \mathrm{mL}$ and 8 $\mathrm{mg} / \mathrm{mL}$ of the extract. However, the percentage of late apoptosis in HepG2 cells was minor. The inhibiting effect of the extract on HepG2 cells proliferation was demonstrated mainly in early stage, implying a potential value of TS leaf as anticancer remedy. 


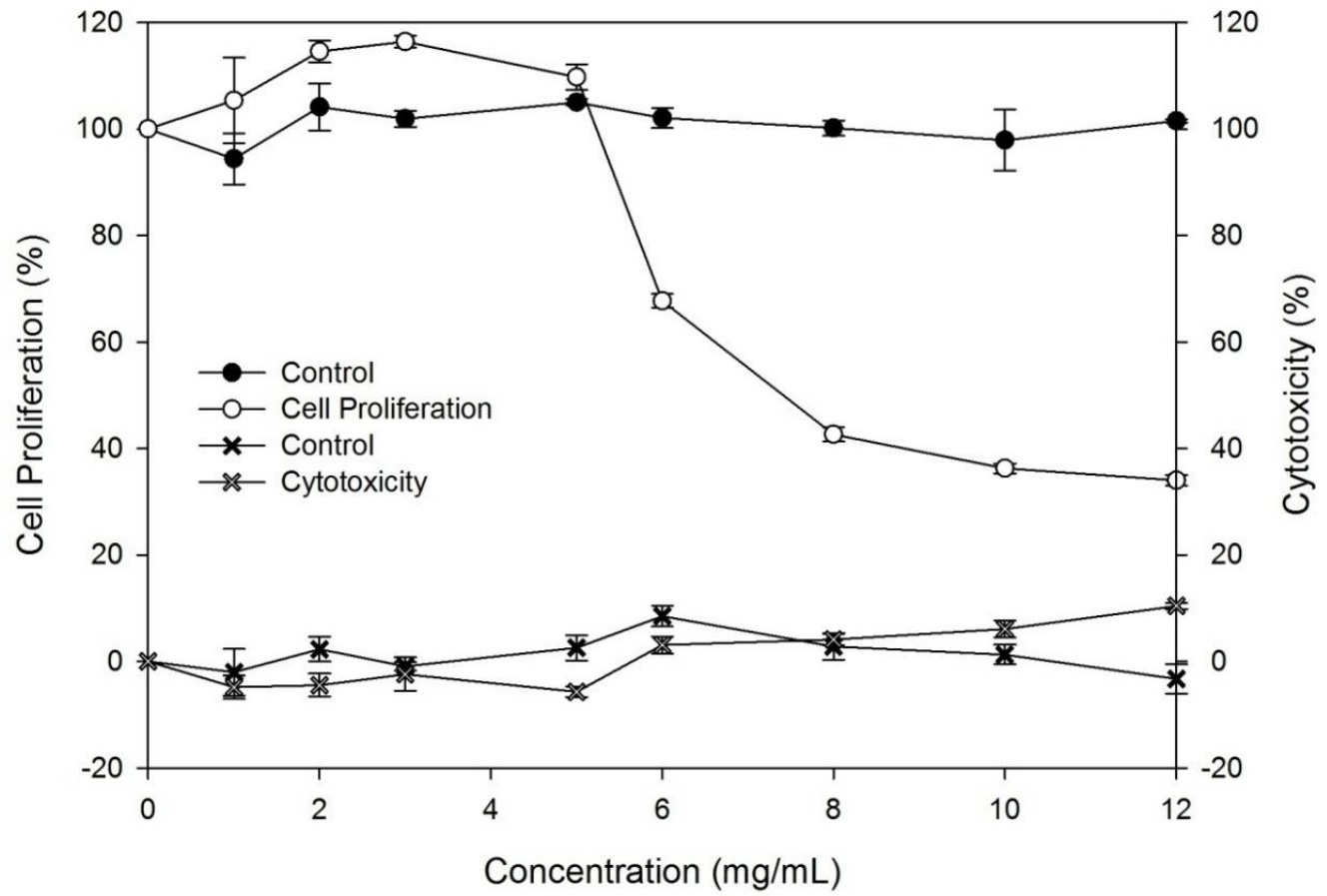

Figure 4: Inhibition of HepG2 cancer cells proliferation and cytotoxicity by TS leaf extract (mean $\pm S D, n=3$ )
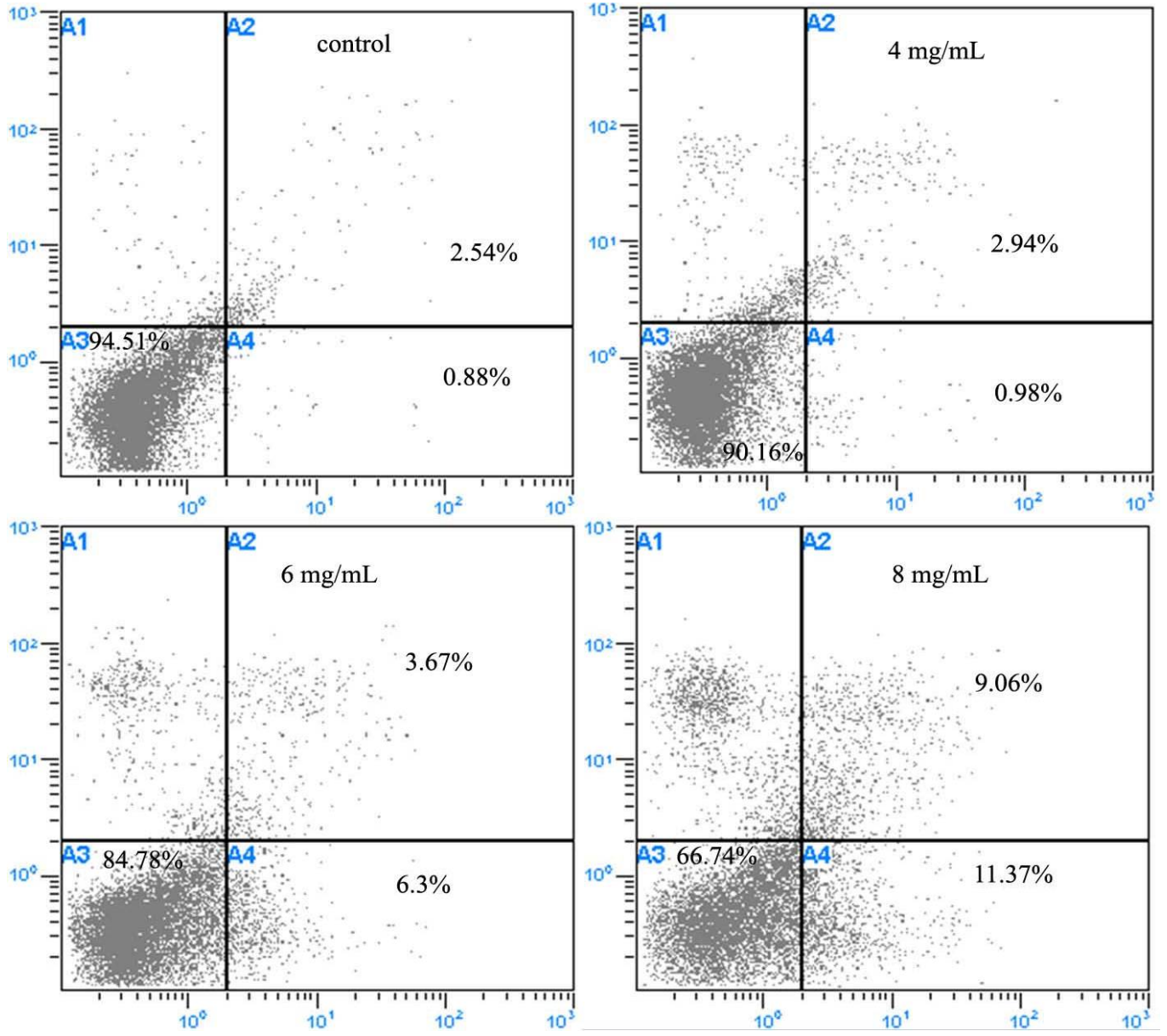

Figure 5: Effect of TS leaf extract on apoptosis in HepG2 cells, determined by flow cytometry with Annexin-V/PI 


\section{DISCUSSION}

This study was focused on antioxidant and antiproliferation activities of TS leaves extract towards HepG2 liver cancer cell line. Quercitrin and rutin were identified as the main flavonoids. Quercitrin (glycosylated form of quercetin), is the most common flavonoid found in nature and has been reported in vegetables and fruits such as apples, grapes, onions, tea [24]. Quercitrin is a bioflavonoid with antioxidant properties and is more easily absorbed than other forms of quercetin [25]. It is protective against UVB irradiation-induced oxidative damage to skin [24]. Rutin is a kind of flavanol glycoside, richly present in black tea, apple skin peels and buckwheat. It has been reported that rutin possesses antioxidant properties, scavenges hydroxyl and superoxide radicals and inhibits lipid peroxidation [26]. Thus the presence of quercitrin and rutin indicate that TS leaf has significant nutrition and health benefits. In plant extracts antioxidant activity cannot be ascertained by a single method due to the complex reactivities of phytochemicals.

Three methods i.e. PSC, ORAC and CAA were used to evaluate antioxidant potential of TS leaves. PSC and ORAC assays incorporate fluorescent probe to monitor reaction. These methods are rapid, precise, reliable, reproducible, and sensitive; and can produce acceptable results comparable to common chemical assays [12]. The assays also take into account the bioavailability, uptake and metabolism of the extract [18].

HepG2 cell culture model is relatively fast, represents the complexity of biological systems and is cost-effective. TS extract had lower $\mathrm{EC}_{50}$ value and higher antioxidant activity in the nowash protocol than in wash-PBS protocol. This is due to the fact that PBS affects extracellular antioxidant activity, thereby reducing the intracellular antioxidant activity. These data demonstrate that the phytochemicals in the extract were able to pass through the cell membrane. Liao et al [27] observed that the inhibitory $50 \%$ concentration values in the DPPH radical-scavenging activity of TS leaf extracts was $0.209 \mathrm{mg} / \mathrm{mL}$. Although the mechanism of different antioxidant activities vary, our results are nonetheless comparable to that of Liao et al [27]. This indicates that TS leaf extract inhibits oxidative stress.

In an interesting study, TS leaf extract significantly inhibited ovarian cancer at the G2 phase in an in vivo xenograft model with no significant toxicity [28]. Furthermore, it has been reported that water leaf extracts of TS $s$ had no acute lethal effect at test dose in male and female mice [29]. Our data also showed that the leaf extract of TS had antitumor effect but no cytotoxic effect.

\section{CONCLUSION}

The findings of this study reveal that TS leaf extract is rich in flavonoids, bioactive compounds responsible for its cellular antioxidant capacity and antitumor effects. These results provide scientific basis for the use of TS as a folk medicine for treating patients with liver cancer. The safety and efficacy of TS leaf makes it a potential natural medicine for managing hepatocellular carcinoma.

\section{ACKNOWLEDGEMENT}

The authors are thankful to Arshad Mehmood Abbasi for his assistance in editing the manuscript for grammatical errors.

\section{REFERENCES}

1. Liu RH. Potential synergy of phytochemicals in cancer prevention: Mechanism of action. J Nutr 2004; 134(12): 3479S-3485S

2. Yang S, Zhao Q, Xiang H, Liu M, Zhang Q, Xue $W$, Song $B$, Yang S. Antiproliferative activity and apoptosisinducing mechanism of constituents from Toona sinensis on human cancer cells. Cancer Cell Int 2013; 13(1):1-8.

3. Dong X, Zhu Y, Bao G, Hu F, Qin G. New limonoids and a dihydrobenzofuran norlignan from the roots of Toona sinensis. Molecules 2013; 18(3): 2840-2850.

4. Wang $C$, Tsai $Y$, Hsieh $Y$, Lin R, Lin C. The aqueous extract from Toona sinensis leaves inhibits microgliamediated neuroinflammation. Kaohsiung J Med Sci 2014; 30(2):73-81.

5. Chen C, Michaelis M, Hsu $H$, Tsai C, Yang $K D, W u Y, J r$. Cinatl J, Doerr HW. Toona sinensis roem tender leaf extract inhibits SARS coronavirus replication. J Ethnopharmacol 2008; 120(1): 108-111.

6. Yu BC, Tsai YT, Ta NL, Yu WJ, Chang SJ. Proteomic analysis of glucose and lipid metabolism in liver of diabetic mice fed with toona sinensis leaf ethanol extract. Ann Nutr Metab 2013; 63: 1292-1292.

7. Li J, Eidman K, Gan X, Haefliger OP, Carroll PJ, Pika J. Identification of (S,S)-gamma-Glutamyl-(cis-S-1propenyl) thioglycine, a Naturally Occurring Norcysteine Derivative, from the Chinese Vegetable Toona sinensis. J Agr Food Chem 2013; 61(31):7470-7476.

8. Hsieh TJ, Tsai YH, Liao MC, Du YC, Lien PJ, Sun CC, Chang F, Wu YC. Anti-diabetic properties of non-polar Toona sinensis Roem extract prepared by supercriticalCO2 fluid. Food Chem Toxicol 2012; 50(3): 779-789. 
9. Hsiang C, Hseu Y, Chang Y, Kumar KJS, Ho T, Yang $H$. Toona sinensis and its major bioactive compound gallic acid inhibit LPS-induced inflammation in nuclear factorkappa $B$ transgenic mice as evaluated by in vivo bioluminescence imaging. Food Chem 2013; 136(2): 426-434.

10. Zhen $H$, Zhang YF, Fang ZJ, Huang ZW, You CG, Shi $P$. Toona sinensis and moschus decoction induced cell cycle arrest in human cervical carcinoma HeLa cells. Evidence-based complementary and alternative medicine: eCAM 2014; 2014:121276.

11. Chu YF, Sun J, Wu XZ, Liu RH. Antioxidant and antiproliferative activities of common vegetables. J Agr Food Chem 2002; 50(23):6910-6916.

12. Chen $Y$, Wang G, Wang $H$, Cheng $C$, Zang G, Guo X, Liu $R H$. Phytochemical profiles and antioxidant activities in six species of ramie leaves. Plos One 2014; 9(9).

13. He X, Liu D, Liu RH. Sodium Borohydride/ChloranilBased assay for quantifying total flavonoids. J Agr Food Chem 2008; 56(20): 9337-9344.

14. Chen Y, Chen G, Fu X, Liu R. Phytochemical profiles and antioxidant activity of different varieties of adinandra tea (Adinandra jack). J Agr Food Chem 2014; 63(1): 169176.

15. Prior RL, Hoang $H, G u L W, W u X L$, Bacchiocca $M$, Howard L, Hampsch-Woodill M, Huang DJ, Ou BX, Jacob R. Assays for hydrophilic and lipophilic antioxidant capacity (oxygen radical absorbance capacity (ORAC(FL)) of plasma and other biological and food samples. J Agr Food Chem 2003; 51(11): 32733279.

16. Huang DJ, Ou BX, Hampsch-Woodill M, Flanagan JA, Prior RL. High-throughput assay of oxygen radical absorbance capacity (ORAC) using a multichannel liquid handling system coupled with a microplate fluorescence reader in 96-well format. J Agr Food Chem 2002; 50(16): 4437-4444.

17. Felice DL, Sun J, Liu RH. A modified methylene blue assay for accurate cell counting. J Funct Foods 2009; 1(1):109-118.

18. Wolfe KL, Liu RH. Cellular antioxidant activity (CAA) assay for assessing antioxidants, foods, and dietary supplements. J Agr Food Chem 2007; 55(22): 88968907.

19. Hsieh CL, Lin YC, Ko WS, Peng CH, Huang CN, Peng RY. Inhibitory effect of some selected nutraceutic herbs on LDL glycation induced by glucose and glyoxal. J Ethnopharmacol 2005; 102(3):357-363.

20. Chen H, Lin Y, Hsieh C. Evaluation of antioxidant activity of aqueous extract of some selected nutraceutical herbs. Food Chem 2007; 104(4): 1418-1424.

21. Ames BN, Shigenaga MK, Hagen TM. Oxidants, antioxidants, and the degenerative diseases of aging. $P$ Natl Acad Sci Usa 1993; 90(17): 7915-7922.

22. Adom KK, Liu RH. Rapid peroxyl radical scavenging capacity (PSC) assay for assessing both hydrophilic and lipophilic antioxidants. J Agr Food Chem 2005; 53(17):6572-6580.

23. Fu YJ, Kadioglu O, Wiench B, Wei ZFet al. Cell cycle arrest and induction of apoptosis by cajanin stilbene acid from Cajanus cajan in breast cancer cells. Phytomedicine 2015; 22(4): 462 - 468.

24. Yin Y, Li W, Son Y, Sun L, Lu J, Kim D, Wang X, Yao $H$, Wang L, Pratheeshkumar P, Hitron AJ, Luo J, Gao N, Shi X, Zhang Z. Quercitrin protects skin from UVBinduced oxidative damage. Toxicol Appl Pharm 2013; 269(2): 89-99.

25. Morand C, Manach C, Crespy V, Remesy C. Quercetin 3O-beta-glucoside is better absorbed than other quercetin forms and is not present in rat plasma. Free Radical Res 2000; 33(5): 667-676.

26. Aruna $R$, Geetha A, Suguna P. Expression of caspase activation recruitment and pyrin domain levels of apoptosis-associated speck-like protein complex in the pancreas of rats subjected to experimental pancreatitis: Influence of rutin administration. Hum Exp Toxicol 2014; 33(9): 940-948.

27. Liao J, Hsu C, Wang M, Hsu W, Chan Y. Beneficial effect of Toona sinensis Roemor on improving cognitive performance and brain degeneration in senescenceaccelerated mice. Brit J Nutr 2006; 96(2): 400-407.

28. Chang H, Hsu H, Su J, Wang P, Chung Y, Chia Y, Tsai L, Wu Y, Yuan SF. The fractionated Toona sinensis leaf extract induces apoptosis of human ovarian cancer cells and inhibits tumor growth in a murine xenograft model. Gynecol Oncol 2006; 102(2): 309-314.

29. Liao J, Chung Y, Yeh J, Lin Y, Lin Y, Wu S, Chan Y. Safety evaluation of water extracts of Toona sinensis Roemor leaf. Food Chem Toxicol 2007; 45(8): 1393 1399. 